2018. JIAL: The Journal of Internationalisation and Localisation, 5:1, 101-137.

\title{
Harnessing the Roar of the Crowd
}

A Quantitative Study of Language Preferences in Video Games of French Players of the Northern Hemisphere

Ugo Ellefsen and Miguel Bernal-Merino

University of Roehampton

London

Through quantitative data analysis, this study explores the attitudes of gamers from different French-speaking locales (Belgium, France, Canada, and Switzerland) in relation to their language preference and opinions of translated material while playing video games. The intended goal is to develop a replicable methodology for data collection about the linguistic preferences of video game players. The research strategy is based on online questionnaires distributed to gamers through social media. The results highlight players' level of satisfaction regarding the localisation of games and suggest that industry strategies put forward till recently may be rather inadequate. Linguistic preferences seem to vary within locales based on factors such as English language proficiency and personal background. The results of this research may serve the implementation of new localisation strategies for video game products in French-speaking countries of emerging markets or other multinational languages. 
2018. JIAL: The Journal of Internationalisation and Localisation, 5:1, 101-137.

Keywords: localisation, reception, video games, audience, French gamers, community

\section{Introduction and hypothesis}

With global sales projected to represent $\$ 108.9$ billion in 2017 , a growth of 7.8\% from the revenues of 2016 (Newzoo 2017), the video game industry is considered as outperforming literature and cinema (Chatfield 2009). The fact that video games are considered as the pinnacle of customised narrative experience (Bernal-Merino 2015, 36) is instrumental to such successes. Video games are a highly personalised experience, as each game session is based on the actions of the participant, and how players are agents of their own miseen-scène (Gagnon 2013, 58). The immersion is reinforced by the interactivity itself but also by the player's understanding of the narrative, further stressing the need for localised products to provide a full experience for gamers in different locales. The localisation of Multimedia Interactive Entertainment Software (MIES) should thus be considered as one aspect of this personalised experience, tailoring the product to fit the specific needs of individuals around the world, for non-English-speaking markets accounts for the highest percentage of income for game developers (Chandler and Deming 2012, 3). 
While scholars and professionals support the idea that localisation affects sales, accurate assessment of the success or failure of video game localisation cannot be truly understood without the input of the gaming community. Video game localisation is a flourishing industry with professional organisations fostering best practices (IGDA game localisation SIG 2017), industry roundtables and summits on the topic of video game localisation (Loc World 2017; GDC 2017), professional and academic networks (Media Across Borders 2017) and many third-party companies specialised on the matter (Keywords 2017; Bug Tracker 2017; Pole to Win 2017; Testronic 2017). Although it seems clear that localisation is a prerequisite to increase playability (Bernal-Merino 2015), the focus on players as end users is a fairly new topic and little research has been undertaken on the matter (Geurts 2014, 4; Fernández Costales 2015, 184). Previous research on the function of video game localisation has stressed the importance of games as an experience rather than a message (O'Hagan 2007). Nonetheless, even if functionalist theories of translation put the purpose and the intended audience as the focus of the translation they do not succeed at connecting translation studies and translation as an activity because of a lack of empirical data (Suojanen et al. 2014, 3).

Considering that the main goal of game localisation is to preserve or even enhance the game experience, the notions of right or wrong in translation are not particularly useful (Fernández Costales 2015, 187) as they “do not tap 
into the knowledge of users" to produce better quality linguistic transfers. While good video game localisation is hardly praised, non-idiomatic adaptations are usually criticised quite vehemently in discussion groups by the gaming community (Dietz 2007, 3). Where professionals claim that quality in localisation is part of a delicate balance between financial and linguistic concerns (Bartelt-Krantz 2011), guidelines for quality assessment in video game localisation are hard to define. This is why the opinion of the end user, rarely taken into account, can be of great help.

The aim of this research is to investigate the linguistic preferences of French-speaking gamers of countries of the Northern hemisphere where French is an official language (Belgium, France, Canada, and Switzerland), through quantitative data analysis. The focus of this study is to explore the habits of video games players based on demographics and language preferences when consuming entertainment media. French is one of the official languages of at least six countries of the Northern hemisphere. On Steam, a US digital distribution platform, French is the $7^{\text {th }}$ most common language (Valve 2017). Although these French speakers express themselves with different dialects, video games are generally translated to suit the need of the biggest market, France in this particular case, which Francophone players in other locales do not always seem to approve of. Linguistic consumer habits of gamers from French-speaking multilingual locales (Belgium, Canada, Switzerland) may differ from those of gamers from monolingual locales (France). For that reason, the multilingual group is less 
2018. JIAL: The Journal of Internationalisation and Localisation, 5:1, 101-137.

likely to favour French localisation. Moreover, the confidence level in English of the multilingual group tends to surpass the level of the monolingual group. Multilingual locales have a higher proportion of users who play games in English and they generally refuse domesticating strategies in translation such as the adaptation of names, dubbing, and censorship.

\section{Theoretical Framework and Literature Review}

The first publications in the field of video game localisation have been defining the process of video game localisation based on best practices of the industry (Chandler and Deming 2012/2005) or establishing the localisation of MIES as a complex and multidisciplinary field of research (Bernal-Merino 2015). Amongst the approaches to localisation, the notion of culturalisation has been stressed as an important geopolitical and cultural dimension which moves video game localisation outside of language per se, into Cultural Studies (Edwards 2011; Bushouse 2015). Research has focussed on the idea that localisation is a new field which needs to be defined within the realm of Translation Studies as a translation of experience rather than text (O’Hagan 2007; O’Hagan and Mangiron 2013; Gagnon 2013; Mandiberg 2012). 
By coining the term 'User-Centered Translation' (UCT), Suojanen et al. (2014) express the need for a new focus in Translation Studies, by moving Translatology closer to the user. UCT differs from previous reader-based approaches because it uses empirical data and practical analysis to assess the impact of the end user in translation (12). By putting forward the notion of usability which is focussed on the interface between the human and the device, the authors turn the focus of translation towards the user experience. Game localisation requires, therefore, "playability" (Bernal-Merino 2015). It is precisely this type of experiential equivalence that previous localisation scholars defined as the level of equivalence that needs to be sought in the adaptation of video games (Mangiron and O’Hagan 2006). Yet, assessment of equivalence cannot be achieved without external input from the player themselves. To correctly measure the preference of the end user, quantitative and qualitative data are needed to bridge the gap between theory and practice because even though "mental models and heuristics are indeed useful for the translator, (...) they always entail a degree of uncertainty, and they work best when combined with empirical usability research" (Suojanen et al. 2014, 93). UCT is opposed to traditional localisation processes such as Quality Assessments (QA) because UCT is an iterative process instead of a definitive one like the latter.

Some studies have been conducted through a mix of user experience and interview-based methods (O'Hagan 2009) but while a user-experience 
study on the skopos of a MIES might provide useful insights to the industry, the size of the sample $(n=1)$ and the fact that it focussed on one game does not provide representative data. Geurts (2015) conducted a quantitative study on the reception of video games, with a sample of 108 Dutch students ranging from 16 to 30 years. The study revealed that Dutch gamers generally play MIES in English and would not play more video games if they were translated into their native language; a conclusion the researcher links to flaws in the current localisation strategies more than actual linguistic preferences. Additionally, the more a gamer falls into the 'extreme gamer' category, the more likely they would play games in a non-native language which suggests that hardcore gamers favour linguistic immersion. One major point highlighted by the research is that Dutch gamers are generally dissatisfied with the quality of the localisation offered to them, criticising the lip synchronisation, voice acting, literalism, etc. (70). While the research draws some thought-provoking conclusions, the sample remains limited in size ( $n=108)$ and is composed mainly of students with a fairly good grasp of English. Fernández Costales investigated whether "players prefer games to be translated by keeping the "look and feel" of the original product and also the cultural elements from the source text" $(2015,185)$. In this research, participants $(n=94)$ have a clear preference for foreignisation over domestication, an element which can be correlated with the fact that they are university students (196). 


\section{Methodology}

Since the goal of this study is to describe the linguistic preferences of Frenchspeaking gamers of different Francophone locales, the choice of a survey as a tool for data collection seems the most appropriate because of its nonintrusive nature, ideal for data collection. The questionnaire designed for this study is a continuity of previous research completed in the context of the reception of localised video games and the methodology partially draws upon those in Geurts (2014) and Fernández Costales (2015). The collected data was analysed with IBM's Statistical Package for the Social Sciences (SPSS) v.22.

\subsection{The tool}

The instrument used to gather data regarding users' preferences is an online questionnaire aptly named Sondage sur les préférences linguistiques des joueurs francophones created using Typeform (www.typeform.com). The questionnaire was made available online on a variety of social platforms 
(Facebook, Reddit, jeuxvideo.com, GamerZ.be, ps4-suisse, retrogaming.ch) between May 16, 2016 and June 14, 2016.

Composed of 24 questions, the survey was divided into five main parts. The first section identified the respondents by age, gender, and by nationality. Section two drew a "linguistic profile" of the participants (native language and level of confidence in English). Section three explored questions in relation to linguistic preferences for audiovisual (AV) and textual content. In section four, the respondent was asked video game preferences regarding language. The fifth section used a five-point Likert scale (strongly agree, agree, neither agree nor disagree, disagree, strongly disagree) for respondents to express their opinion regarding video game localisation statements.

\section{Research Sample}

4.1 General demographic overview

The research sample is composed of gamers $(n=726)$ from four different countries where French is an official language (Belgium, Canada, France, and Switzerland). Although the total number of respondents was originally 742 , 
2018. JIAL: The Journal of Internationalisation and Localisation, 5:1, 101-137.

16 respondents have been disqualified as they were either non-Frenchspeaking natives or nationals of countries that are outside the scope of the research. As shown in Figure 1, there is an over-representation of Canadians (mainly Quebecers) in the sample, which is related to this researcher's own nationality and professional network.

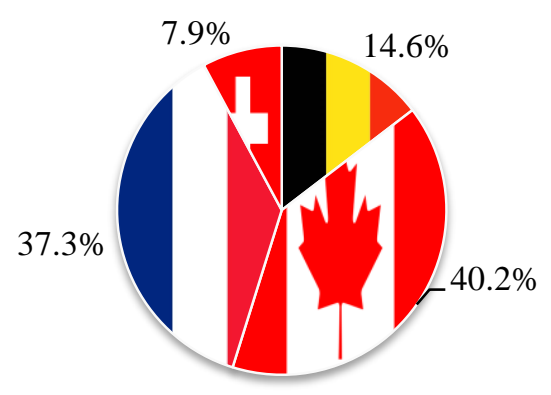

\section{Figure 1 Nationality of respondents}

Figure 2 below illustrates the gender distribution of the sample. The sample is composed of 561 male and 145 female respondents while 20 participants decided to not disclose their gender. A sample of $20 \%$ women is small in relation to the presence of the female players in the gaming community which fluctuates between $41 \%$ in America (ESA 2017,7 and ISFE 2012 in Fernández Costales 2016, 188) to 47\% in France (Beuré et al. 2014, 9), and 52\% in the UK (Internet advertising bureau 2014 in Jayanth 2014). Nevertheless, these results do not prove to be problematic to the analysis of the sample because previous studies on the topic of video game localisation have shown that there is no substantial difference in attitude between male 
2018. JIAL: The Journal of Internationalisation and Localisation, 5:1, 101-137.

and female players when it comes to their video game language preferences (Fernández Costales 2015, 188).

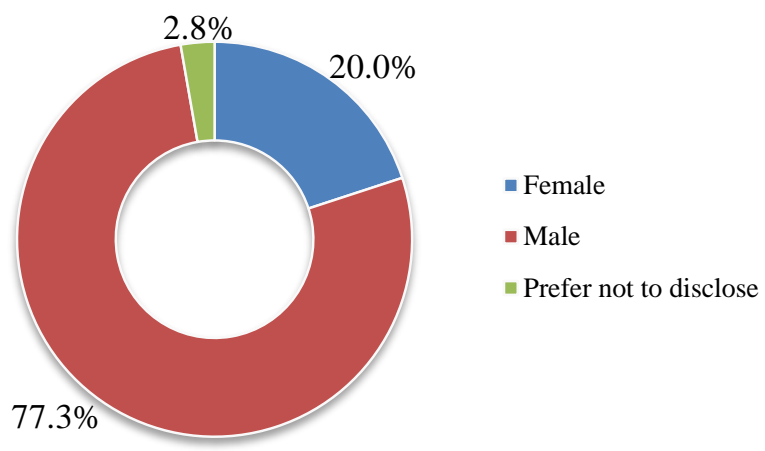

Figure 2 Distribution of respondents (by the gender they identify as)

In the French-speaking world, studies show that the average gamer is 31.5 years old (Beuré et al. 2014, 5) which explains why the majority of the sample falls into the 25 to 34 -year-old age range. It is also the age range of the average American gamer according to the industry (ESA 2017, 7).

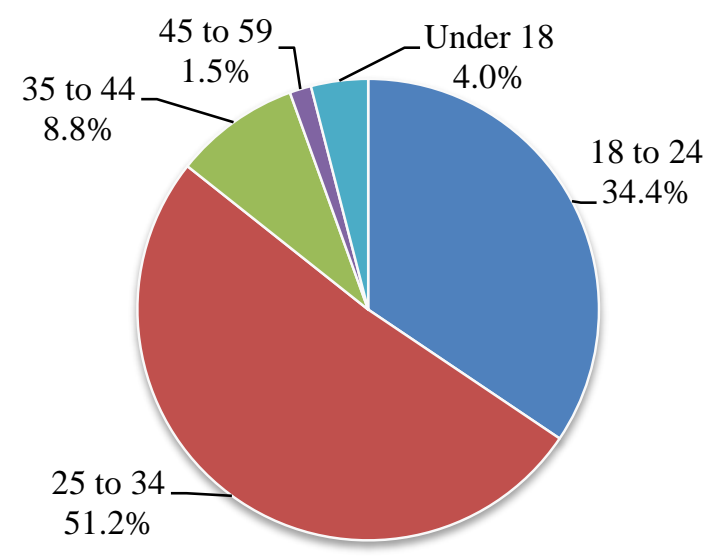

Figure 3 Age bands of the participants of the study 
2018. JIAL: The Journal of Internationalisation and Localisation, 5:1, 101-137.

With an average degree of confidence in English of 7.7 out of 10, the participants score fairly high considering that $37.2 \%$ of all Francophones surveyed assumed that they have a level of English of 9 out of 10 and above, almost equivalent to that of a native speaker (see Figure 4 below) a result not unlike previous studies in this field (Fernández Costales 2016, 189). While this question is in no way a representative measurement of the linguistic abilities of the sampled population, this high level of confidence is achieved through two major factors. One of these factors is that gamers in general may have a higher level of English proficiency than the majority of non-native speakers of English, an assumption that still needs to be proven. The second reason is that $40.2 \%$ of the respondents were from Canada, where English and French are both official languages. In fact, $71.2 \%$ of the participants who claimed to have a perfect (10 out of 10) mastery of English were FrenchCanadians. The main goal of this question was to gather evidence of a higher level of confidence in English amongst speakers of French from multilingual locales. 


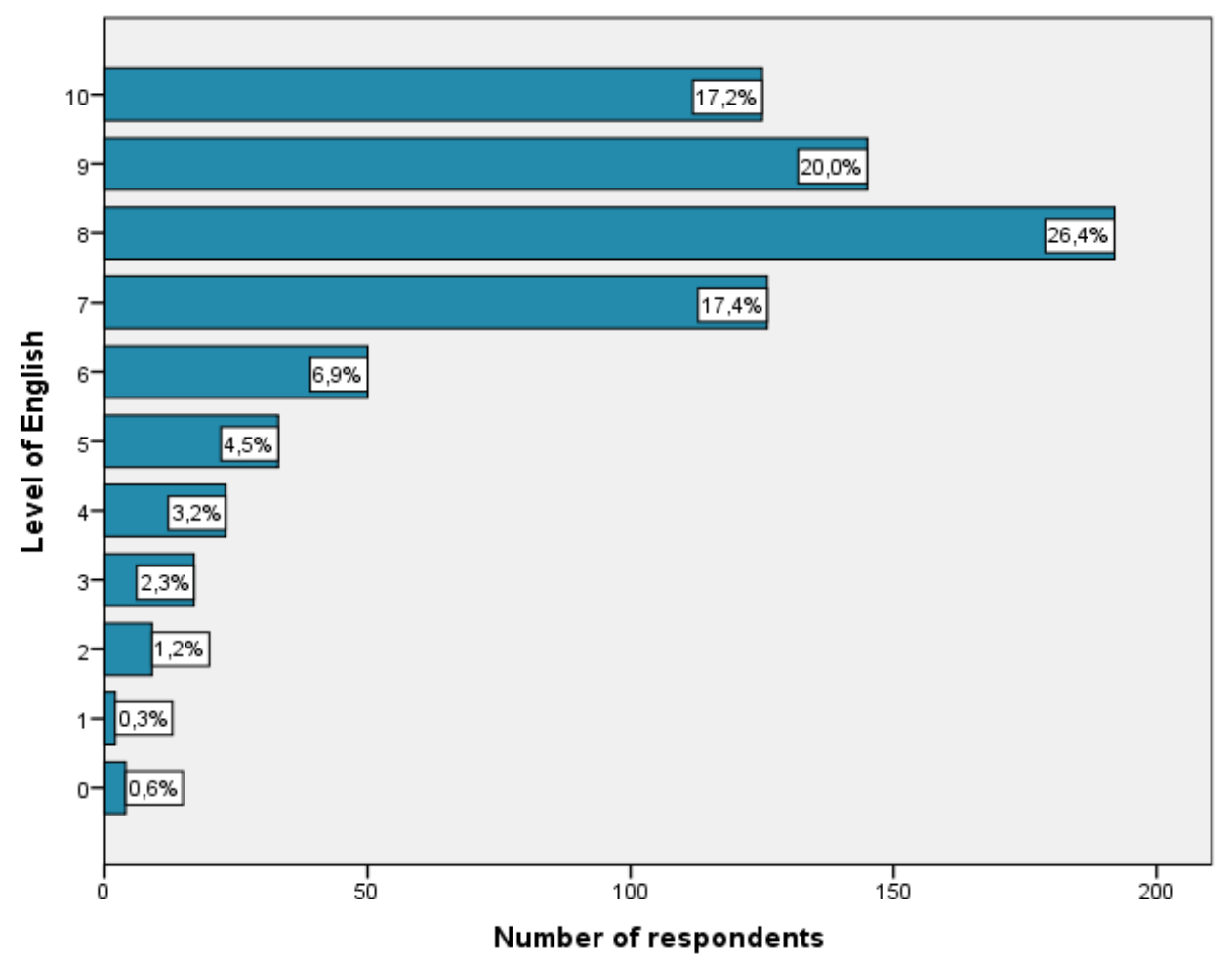

Figure 4 Self-assessed level of confidence in English of the participants

Previous studies have been undertaken based on the assumption that gamers can be categorised by the amount of time they spend on video games. These publications have based their analysis on the ideas that serious gamers have different linguistic preferences than casual ones (Geurts 2014). Figure 5 below shows the hours per week of respondents. 


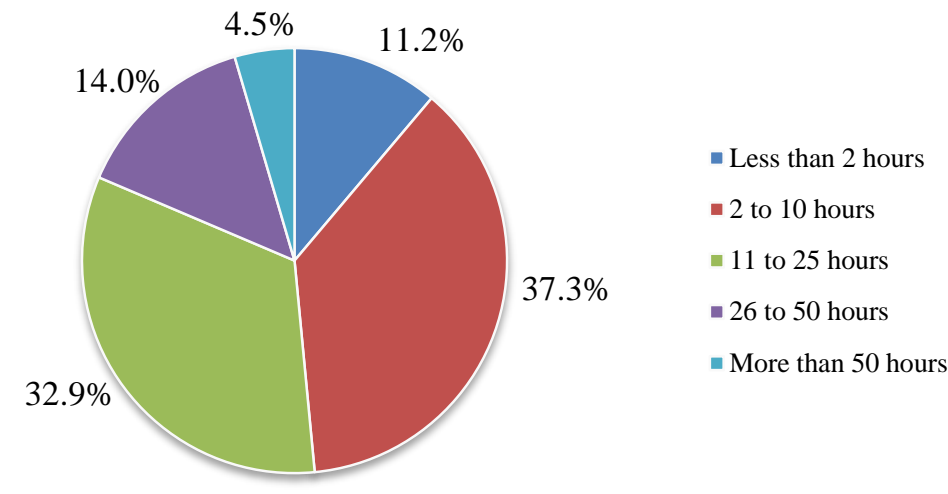

Figure 5 Hours per week spent on video games by the participants

As shown in figures 5 and 6 , while $70.2 \%$ of gamers fall into the 2 to 25-hour brackets, the amount of money they spend monthly on video gamerelated content is quite evenly distributed over the sample.

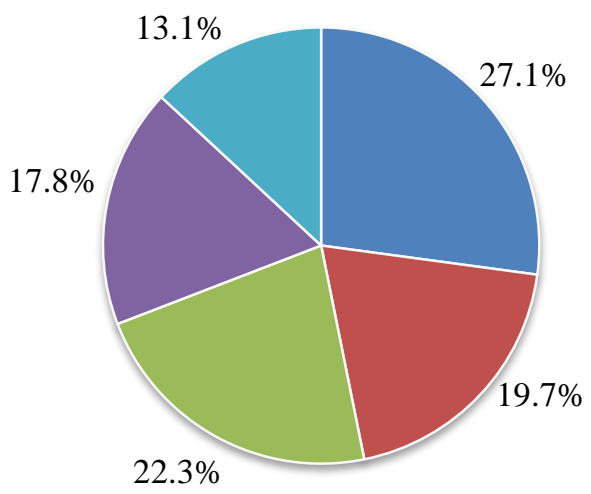

- Less than $\$ 5 / € 4$ per month

- $\$ 6 / € 5$ to $\$ 10 / € 9$ per month

- $\$ 11 / € 10$ to $\$ 20 / € 17$ per month

- $\$ 21 / € 18$ to $\$ 40 / € 35$ per month

- More than $\$ 40 \$ / € 35$ per month

Figure 6 Amount of money spent per month on gaming hobby (purchases, hardware, subscription, etc.) by the participants

The frequency of gaming can help correlate the type of player based on the intensity of their gaming activity and their behaviour when it comes to 
linguistic content. The assumption behind isolating 'casual' and non-gamers from 'serious gamers' is that they might have different preferences regarding game localisation (Geurts 2014, 24). Dedicated players can be identified as any respondent spending as much or more than $\$ 11 / € 10$ to $\$ 20 / € 17$ and playing as much or more than 11 to 25 hours per week. 508 respondents were thus labelled as 'serious gamers'. In any case, the analysis of the results has shown that the differences in attitudes between the global sample and the serious gamers are minimal on all items of the questionnaire. On the other hand, while the low level of variation between the two groups showed that isolating the serious gamers was a fruitless task, the financial involvement and time allocation to video gaming as an activity supports the representativeness of the sample considering that the preferences expressed through the survey were mainly (70\%) those of a committed community akin to fandom, understood as "an institution of theory and criticism, a semistructured space where competing interpretations and evaluations of common texts are proposed, debated and negotiated and where readers speculate about the nature of the mass media and their own relationship to it" (Jenkins 2013, 86). 


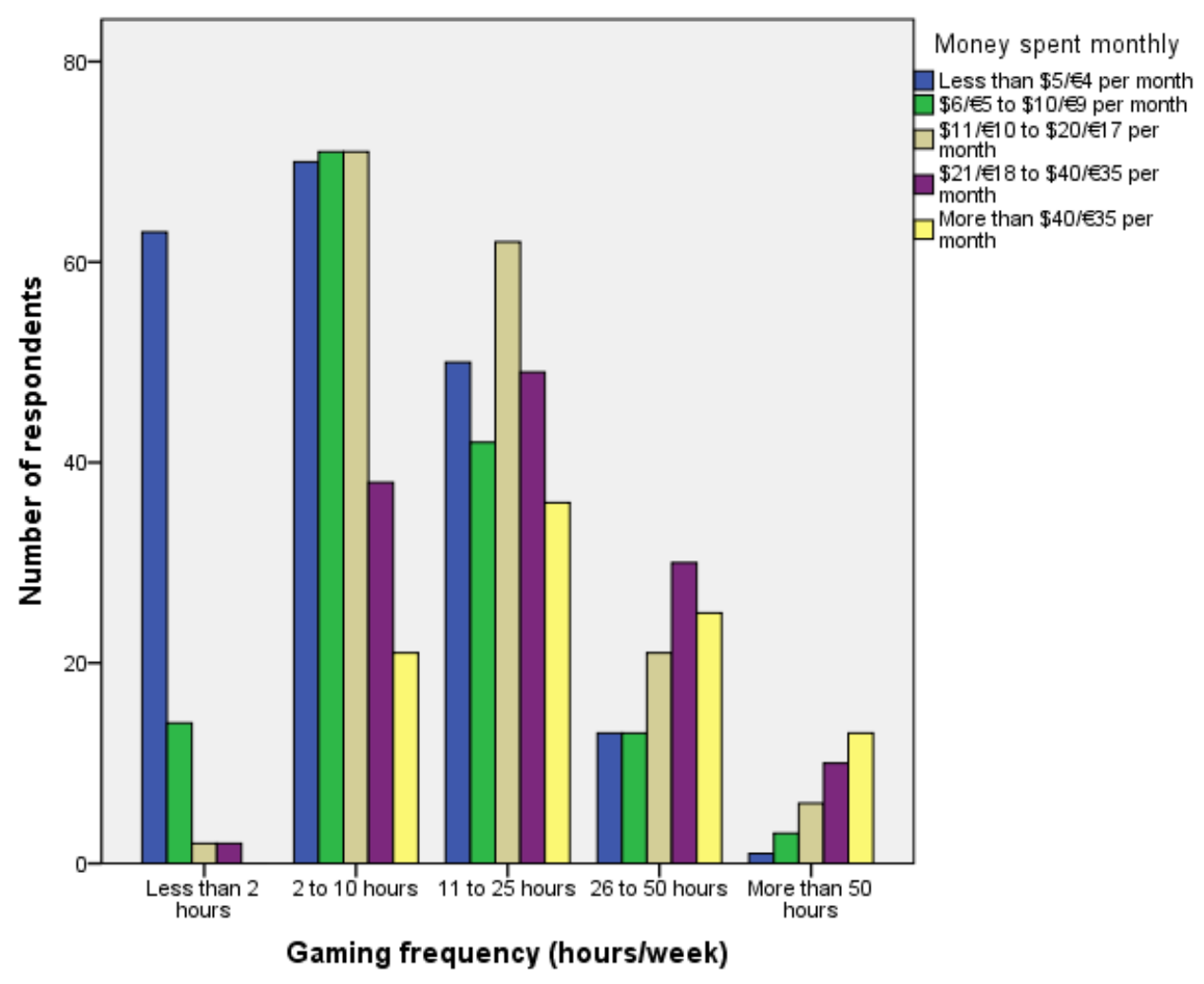

Figure 7 Relation between the frequency of gaming and the amount of money spent monthly on video games

\section{Analysis}

Consumer behaviour of French video game players in relation to language in entertainment products 
2018. JIAL: The Journal of Internationalisation and Localisation, 5:1, 101-137.

The underlying reason behind the investigation of consumer behaviour regarding passive media is related to the similarities these entertainment products share with MIES as narratives, but also because they are all part of transmedia strategies. Literature, films and video games are nowadays all intertwined in a common thread and benefit from each other to produce more paratext (Bernal-Merino 2016b). Considering how video games complement and compete with passive media for the consumer's attention, the way the latter is enjoyed interlingually is of particular importance to define better practices. Most video games can be played with subtitles and many games are praised for their narrative qualities but the captions rarely do the products any justice as they generally do not obey to any kind of cinematic convention (Mangiron 2013). Questions 3a and 3b investigated how the participants watch audiovisual products in English and other foreign languages. 
Table 1 Linguistic preferences of the participants regarding English audiovisual material

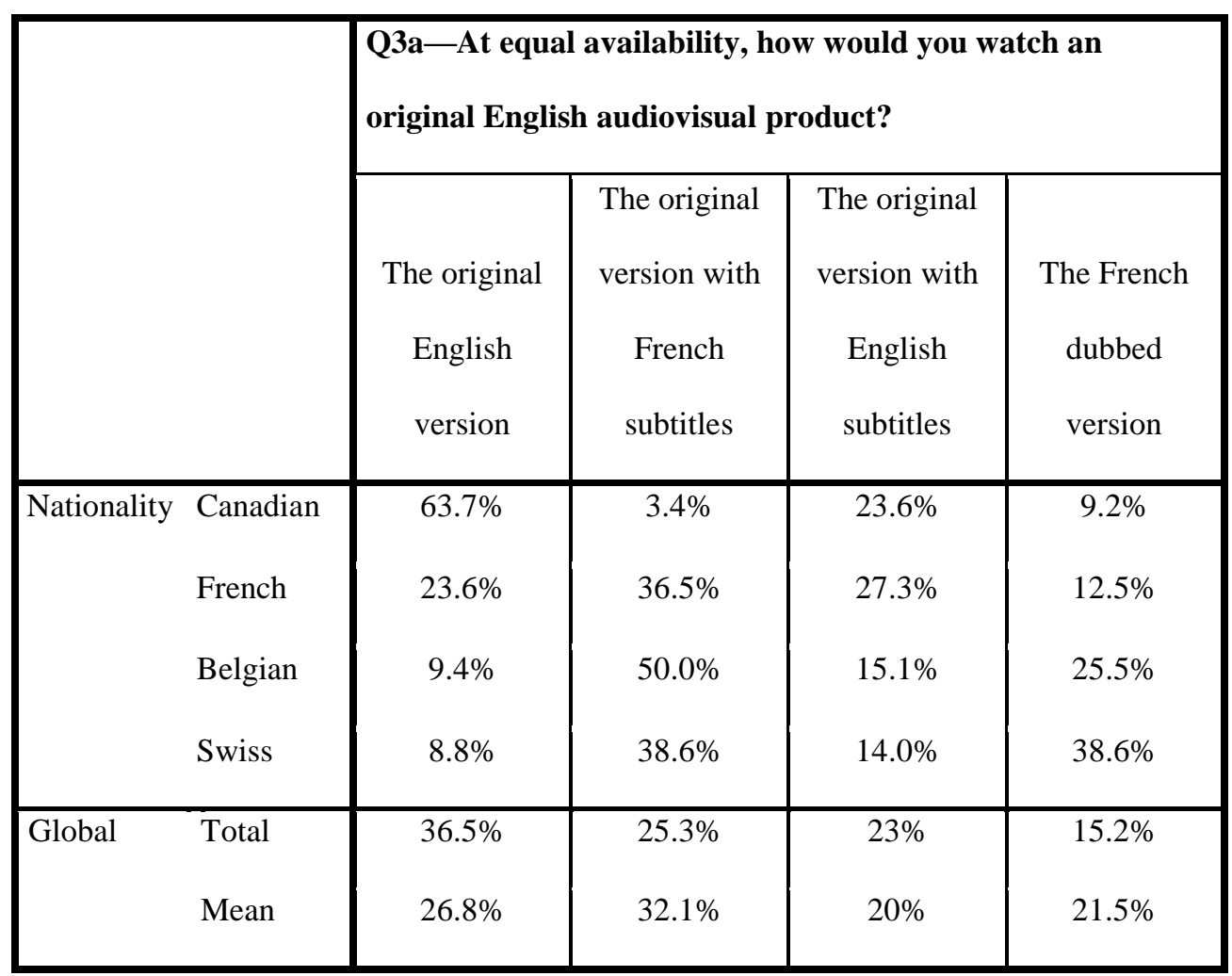

Table 2 Linguistic preferences of the participants regarding foreign language (neither English nor French) audiovisual material 


\begin{tabular}{|c|c|c|c|c|c|}
\hline & \multicolumn{4}{|c|}{$\begin{array}{l}\text { Q3b-At equal availability, how would you watch a foreign } \\
\text { language (non-English) audiovisual product? }\end{array}$} \\
\hline & & $\begin{array}{l}\text { The original } \\
\text { with French } \\
\text { subtitles }\end{array}$ & $\begin{array}{c}\text { The original } \\
\text { with English } \\
\text { subtitles }\end{array}$ & $\begin{array}{c}\text { The English } \\
\text { dubbed } \\
\text { version }\end{array}$ & $\begin{array}{c}\text { The French } \\
\text { dubbed } \\
\text { version }\end{array}$ \\
\hline \multirow[t]{4}{*}{ Nationality } & Canadian & $30.8 \%$ & $40.1 \%$ & $7.9 \%$ & $21.2 \%$ \\
\hline & French & $52.0 \%$ & $17.7 \%$ & $4.4 \%$ & $25.8 \%$ \\
\hline & Belgian & $43.4 \%$ & $17.9 \%$ & $1.9 \%$ & $36.8 \%$ \\
\hline & Swiss & $43.9 \%$ & $12.3 \%$ & $0.0 \%$ & $43.9 \%$ \\
\hline \multirow[t]{2}{*}{ Global } & Total & $41.6 \%$ & $26.3 \%$ & $5.1 \%$ & $27 \%$ \\
\hline & Mean & $42.5 \%$ & $22 \%$ & $3.6 \%$ & $31.9 \%$ \\
\hline
\end{tabular}

The analysis of both Q3a and Q3b illustrates a tendency to favour subtitles over dubbing in most surveyed locales. The lack of popularity of dubbing can be explained by the high confidence in English amongst the participants and by a rising tendency to watch AV products in the original language even in countries where dubbing used to be the main means of interlingual transfer (Fernández Costales 2016, 195). Remarkably, subtitles are also used intralingually quite significantly amongst Canadians (23.6\%) and French (27.3\%) participants. This preference can be explained by the fact that intralingual subtitles improve understanding of the aural channel and facilitate language acquisition (Danaan 2004 ; Caimi 2006). 
The Canadian participants differ quite significantly from the rest of the sample, notably by their marked $(63.7 \%)$ preference for the English original and even for English subtitles over French subtitles in foreign language $(40.1 \%)$ audiovisual products. While this can be connected to the idea that the Canadian participants' mean regarding their level of confidence with English (8.62 out of 10) is higher than the global mean (7.71 out of 10), it may express a refusal to accept the predominance of the continental variety of French in translation, supporting the research hypothesis in this regard.

Curiously, the results of Q3a and Q3b also show that Swiss and Belgian participants would generally prefer to watch audiovisual material using French subtitles and they are the most likely to watch the French dubbed versions. These results can be partially explained by a lower-than-the-average mean regarding the self-assessed level of English proficiency of the Belgians (6.64) and the Swiss (6.35) and by the possibility that because these Francophone communities are linguistic minorities in their respective countries, the participants have a stronger desire to enjoy products in their native language as it is a cultural identity-defining feature. 
Table 3 Linguistic preferences of the participants regarding English

\section{literature}

\begin{tabular}{|cc|c|c|}
\hline \multirow{2}{*}{} & & \multicolumn{2}{|l|}{ Q3c-When you read a book originally written in } \\
English, which version do you read? \\
\cline { 2 - 4 } & The English original & The French translated version \\
\hline Nationality & Canadian & $68.2 \%$ & $31.8 \%$ \\
& French & $43.5 \%$ & $56.5 \%$ \\
& Belgian & $25.5 \%$ & $74.5 \%$ \\
& Swiss & $19.3 \%$ & $80.7 \%$ \\
\hline Global & Total & $48.9 \%$ & $51.1 \%$ \\
& Mean & $39.1 \%$ & $60.9 \%$ \\
\hline
\end{tabular}

The results of Q3c displayed in table 3 regarding textual content are also consistent with the answers to previous questions, as a fair majority of Canadian respondents $(68.2 \%)$ prefer to read printed material originally written in English in the original language where $56.5 \%$ to $80.7 \%$ of the continental Francophones participants prefer the translated version. The preference for translated textual content is still more prevalent amongst the Belgians and the Swiss than the French which supports the data from Q3b regarding the use of language as a strong cultural identity-defining statement. 
2018. JIAL: The Journal of Internationalisation and Localisation, 5:1, 101-137.

\subsection{Consumer Behaviour in Relation to Language in Video Games}

Ultimately, the main reason for localising a game in a given language is to reach more people. While sales number confirm that France should be considered as amongst the top ten countries for which a video game should be localised (Newzoo 2017; Valve 2017), data still needs to be collected to assess the impact of French localisation on the French-speaking markets, notably outside of France. Considering that international versions of MIES are generally perceived to be of lower quality by gamers (Chandler and Deming 2012,3) and based on the analysis of the data regarding the preference of the audience in textual and audiovisual content, a clear tendency to opt for the English language when playing video games should be expected. 
Table 4 Language preferences of participants for video games developed in foreign (non-French) languages

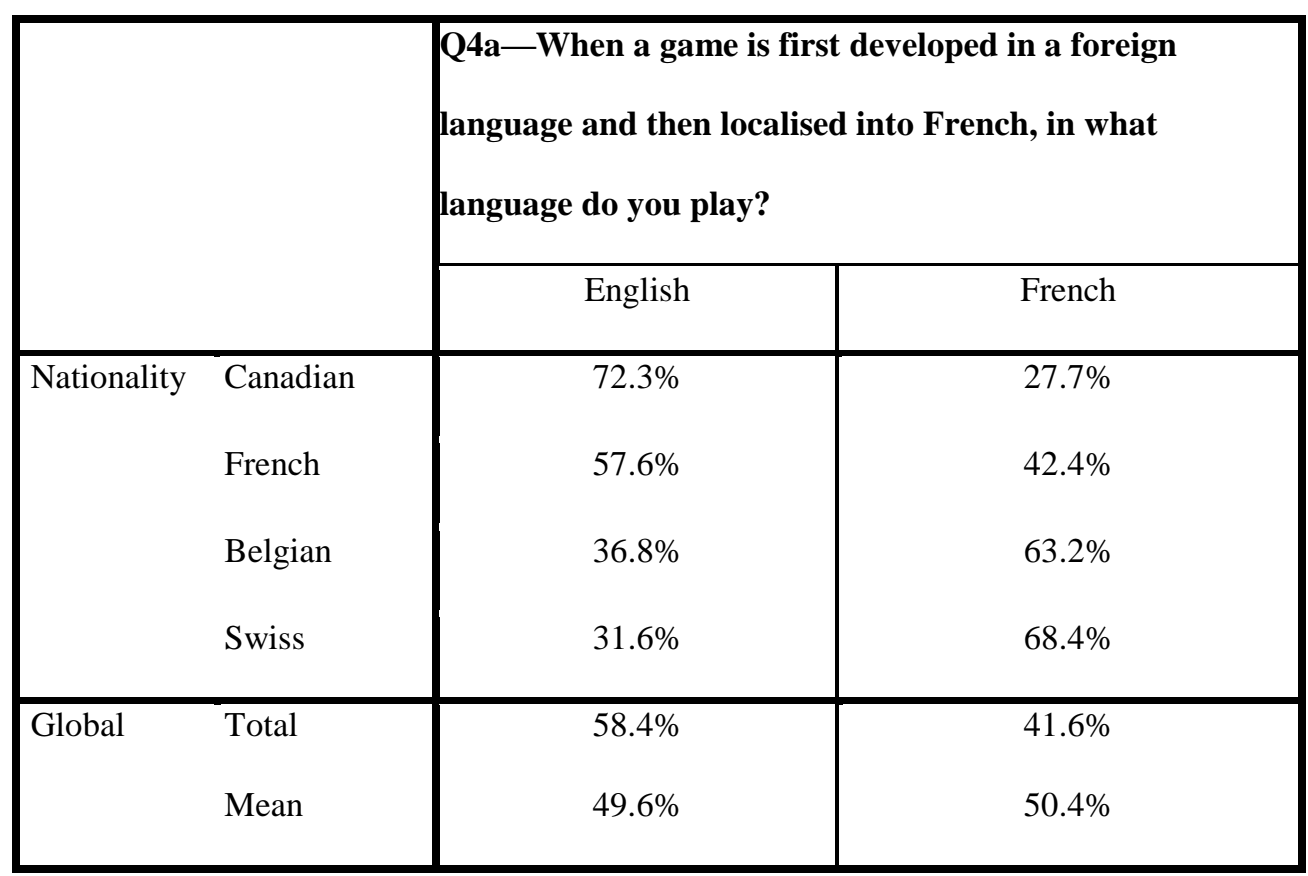

The data in Table 4 regarding the language in which the participants chose to play a video game in are consistent with the data from previous questions in section 3 regarding passive media. Where Canadian participants almost adamantly refused to play translated MIES, the Belgians and Swiss generally preferred the French version. The unexpected results can be found in the French participants, who picked mainly (57.6\%) the English setting rather than the translated version. For a nation considered as the worst European country regarding English language proficiency (Education First 2015), these results come as a surprise. These answers can still be explained by a higher mean in the level of self-assessed English proficiency of the 
French participants ( 7.45 out of 10$)$. However, these numbers should not be interpreted as validating or invalidating the need for French localisation in video games in Francophone locales but rather as a means to measure the reach of French localisation in primary markets such as France and the rest of the Francophone world.

While the analysis of the results so far show that there is a notable tendency to play games in English amongst a majority of French-speaking players, notably in Canada and France, it is harder to decide whether it is a language-related issue or a perception that the translated work is a noncanonical ersatz of the original experience. The results displayed in Table 5 regarding the linguistic preferences of players for a game originally developed in French, involving French intellectual property or taking place in a French context such as Astérix can be interpreted as a control question and shed light on the issue. Considering that the data shows very strong preferences of the participants towards the French version, the results reaffirm the idea that the studied sample would rather choose a game as close to the original as possible as opposed to rejecting the game based on an inclination for English. Even if the proportion of Canadian participants still refusing to play games in French is higher than the average of the European respondents, their numbers are significantly lower and are more attuned to the results of the rest of the French speakers. Considering that the previous results regarding audiovisual material and video games almost showed reluctance to 
2018. JIAL: The Journal of Internationalisation and Localisation, 5:1, 101-137.

opt for French language products amongst the Canadians, the analysis of Q4b supports the hypothesis regarding the perception by some members of the gaming community that video game localisation in its current state is imperfect and that the issue is not language transfer itself but the perception of the community towards localised content, an attitude supported by previous disappointment in relation to the French adaptation of video games. The case of the localised version of Final Fantasy VII is infamous amongst the French gaming community for being a patent example of a mediocre translation of an original game many players consider as a milestone of the series (Laurent 2015). 
Table 5 Language preferences of participants for video games developed in French

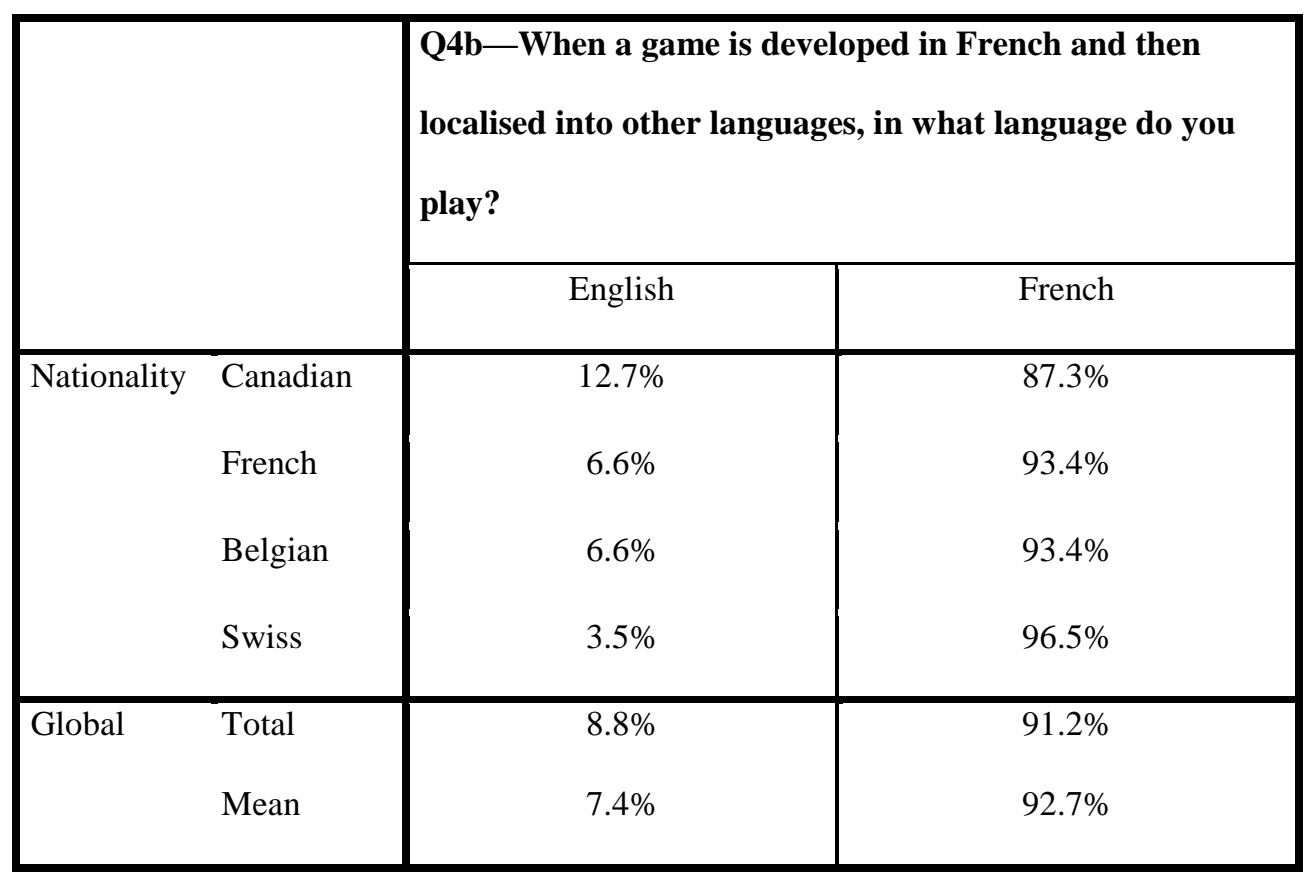

The analysis of $\mathrm{Q} 4 \mathrm{c}$ in Table 6 investigates further the previous findings regarding the perception of translation and the desire for gamers to experience a product that is as genuine or as close to the original design as possible. Considering that the results converge towards the means, this question seems to show a clear pattern within the sample where approximately $65 \%$ of the French-speaking gamers would rather play a game in a language related to the context of the narrative with interlingual subtitles than an English or French version. The idea is to explore whether gamers would play MIES such as Assassin's Creed II in Italian or the Metro series in Russian as these are the languages that befit the cultural context of these 
2018. JIAL: The Journal of Internationalisation and Localisation, 5:1, 101-137.

narratives. Like Q4b, this question can be used as a control question regarding Q4a as the results do not show a general refusal of a given locale to rely on the French localised version. The results can be analysed as a preference for original, genuine source content rather than over-domesticated replicas.

Table 6 Customisation of language preferences based on the context of the video game

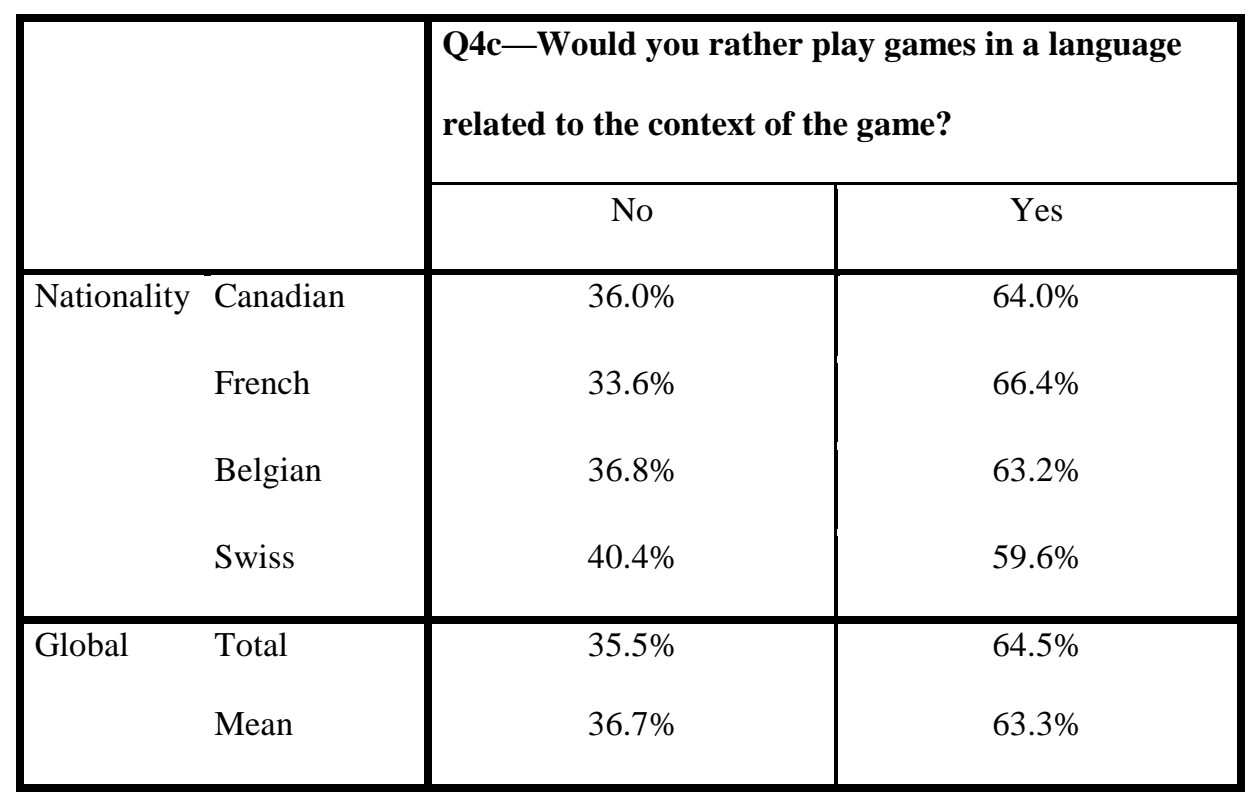

5.2 Consumer's opinions regarding the localisation of video games

Although the goal of this study is to provide quantitative rather than qualitative data to describe the preferences of the French-speaking gamers, the participants were able to express some of their opinions regarding video game localisation in the last section of the questionnaire. Considering that the 
2018. JIAL: The Journal of Internationalisation and Localisation, 5:1, 101-137.

Likert scale used to survey the opinions of the respondents is in five scale and has a neutral zone, the analysis of the results will focus mostly on the two positive and two negatives distributions of the scale to provide insights.

Table 7 Opinion of the respondents about whether all games should be localised into French

\begin{tabular}{|c|c|c|c|c|c|}
\hline \multirow{2}{*}{} & \multicolumn{3}{|l|}{ Q5c-All video games should be localised into French. } \\
\cline { 2 - 6 } & Fully agree & Agree & Neutral & Disagree & $\begin{array}{c}\text { Fully } \\
\text { disagree }\end{array}$ \\
\hline Nationality Canadian & $16.1 \%$ & $26.7 \%$ & $29.5 \%$ & $16.8 \%$ & $11.0 \%$ \\
French & $9.6 \%$ & $21.8 \%$ & $29.2 \%$ & $27.7 \%$ & $11.8 \%$ \\
Belgian & $7.5 \%$ & $25.5 \%$ & $36.8 \%$ & $18.9 \%$ & $11.3 \%$ \\
Swiss & $17.5 \%$ & $21.1 \%$ & $36.8 \%$ & $17.5 \%$ & $7.0 \%$ \\
\hline Total & $12.4 \%$ & $24 \%$ & $31.3 \%$ & $21.3 \%$ & $11.1 \%$ \\
Mean & $12.7 \%$ & $23.8 \%$ & $33.1 \%$ & $20.2 \%$ & $10.3 \%$ \\
\hline
\end{tabular}

While the preference of players for English or French in video games highlighted in Q4a gives a decent idea of how many users decide to play games in French, it does not give any measure regarding the value of French localisation for Francophone users. Q5c explores how valuable the localisation of video games for French users is, based on the notion that all games should be made available to French speakers through translation. While the surveyed French participants would rather not have all video games 
translated into French with $39.5 \%$ of them disagreeing or fully disagreeing with the statement, the global results show that Francophones are generally favourable towards French localisation for all video games with a means of $36.5 \%$ supporting this statement. Surprisingly, the locale that has the strongest positive opinion regarding the statement is Canada; with $42.8 \%$ of the Canadian participants agreeing to a certain extent to the idea of localising all games into French. While this locale has rejected most of the earlier propositions when it comes to its preference of French translation of any content, choosing to watch or play the original or the English version and sometimes even refusing French subtitles over English ones when provided with the choice (see the results of Q3b). This situation can still be explained by the fact that, as previously discussed through the Belgian and Swiss answers to earlier questions, language is an identity defining characteristic of multilingual populations, notably in the North American situation where French speakers are surrounded by the English language. 
Table 8 Opinion of the respondents regarding the localisation of a video game as a way to make the mechanics of the game easier to understand

\begin{tabular}{|cc|c|c|c|c|c|}
\hline \multirow{2}{*}{} & \multicolumn{6}{|l|}{ Q5d-The mechanics of a given video game are easier to } \\
& & understand when it is adapted into French. \\
\cline { 3 - 7 } & Fully & & & & Fully \\
& agree & Agree & Neutral & Disagree & disagree \\
\hline Nationality & Canadian & $15.8 \%$ & $28.8 \%$ & $22.6 \%$ & $18.8 \%$ & $14.0 \%$ \\
& French & $17.7 \%$ & $35.8 \%$ & $26.2 \%$ & $14.8 \%$ & $5.5 \%$ \\
& Belgian & $18.9 \%$ & $40.6 \%$ & $20.8 \%$ & $12.3 \%$ & $7.5 \%$ \\
& Swiss & $19.3 \%$ & $47.4 \%$ & $21.1 \%$ & $10.5 \%$ & $1.8 \%$ \\
\hline Global & Total & $17 \%$ & $34.5 \%$ & $23.9 \%$ & $15.8 \%$ & $8.9 \%$ \\
& Mean & $18 \%$ & $38.15 \%$ & $22.7 \%$ & $14.1 \%$ & $7.2 \%$ \\
\hline
\end{tabular}

Gameplay is part of the general user experience of MIES and is the core of the implicit convention between the player and the game. While professionals recommend streamlined mechanics to improve the experience (Rose 2008), being unable to understand the language will always complexify the learning curve and is perceived as having a potentially negative impact on sales figures. The analysis of the results of Q5d in Table 8 shows that a majority of the participants agree to a certain extent with the idea that French localisation facilitates the understanding of the mechanics of a given game. This question illustrates a shift in player's opinion towards a more positive 
outlook on localisation as an element that improves how a player understands the game.

Table 9 Opinion of the respondents regarding the French localisation of a video game as facilitating the communication between players

\begin{tabular}{|cc|c|c|c|c|c|}
\hline \multirow{2}{*}{} & \multicolumn{6}{|l|}{ Q5e-Communication between players is easier when a } \\
game is adapted into French. \\
\cline { 3 - 7 } & & Fully & & & \\
agree & Agree & Neutral & Disagree & disagree \\
\hline Nationality & Canadian & $9.6 \%$ & $18.2 \%$ & $31.5 \%$ & $25.3 \%$ & $15.4 \%$ \\
& French & $11.4 \%$ & $29.5 \%$ & $27.3 \%$ & $21.4 \%$ & $10.3 \%$ \\
& Belgian & $11.3 \%$ & $41.5 \%$ & $25.5 \%$ & $16.0 \%$ & $5.7 \%$ \\
& Swiss & $10.5 \%$ & $43.9 \%$ & $24.6 \%$ & $17.5 \%$ & $3.5 \%$ \\
\hline Global & Total & $10.5 \%$ & $28.2 \%$ & $28.2 \%$ & $22 \%$ & $11.2 \%$ \\
& Mean & $10.7 \%$ & $33.3 \%$ & $27.2 \%$ & $20 \%$ & $8.7 \%$ \\
\hline
\end{tabular}

With the advent of the hyper-connected world came the massively multiplayer online role-playing game (MMORPG) such as World of Warcraft and other games where the interaction between players happens online. Q5e investigated the perception of French players regarding the notion that the French localisation of a video game facilitates the communication between players. While $27.8 \%$ to $54.4 \%$ of the surveyed gamers agree to a certain extent that communication between players is made easier by the localised version, $40.7 \%$ of the Canadian respondents disagree with this proposition. 
2018. JIAL: The Journal of Internationalisation and Localisation, 5:1, 101-137.

These results can be explained by the fact that most French-Canadians will eventually communicate with English-speaking players in their online interactions as the servers on which games are hosted are generally zoned by geographical ensembles. Games such as World of Warcraft, Counter Strike: Global Offensive or DotA 2 will be played on US servers which are English language-based and while it could be possible for a French-speaking player to create an account on a European server, latency issues and the different time zones would negatively impact their game experience. Another reason which could explain why also $31.7 \%$ of French gamers surveyed disagree with the statement of Question 5e was brought up through Reddit where some participants stated that they still want to exchange with the rest of the world to discuss strategies or game mechanics, and that when they understand the game in English there are less "intellectual gymnastics" involved to get the answers they seek. 
Table 10 Opinion of the respondents regarding the translation of names, toponyms and cultural references

\begin{tabular}{|cc|c|c|c|c|c|}
\hline \multirow{2}{*}{} & & \multicolumn{6}{|l}{ Q5f-Names, places and cultural references in video games } \\
should never be translated. \\
\cline { 3 - 7 } & & Fully & & & & Fully \\
agree & Agree & Neutral & Disagree & disagree \\
\hline Nationality & Canadian & $51.4 \%$ & $20.9 \%$ & $16.8 \%$ & $8.6 \%$ & $2.4 \%$ \\
& French & $33.6 \%$ & $30.6 \%$ & $21.8 \%$ & $9.6 \%$ & $4.4 \%$ \\
& Belgian & $46.2 \%$ & $28.3 \%$ & $19.8 \%$ & $4.7 \%$ & $0.9 \%$ \\
& Swiss & $35.1 \%$ & $26.3 \%$ & $28.1 \%$ & $7.0 \%$ & $3.5 \%$ \\
\hline Global & Total & $43.1 \%$ & $25.7 \%$ & $19.9 \%$ & $8.1 \%$ & $3.1 \%$ \\
& Mean & $41.6 \%$ & $26.5 \%$ & $21.6 \%$ & $7.5 \%$ & $2.8 \%$ \\
\hline
\end{tabular}

In video game localisation studies, some researchers have expressed that the best strategy for the translation of toponyms in video games is nontranslation. This conclusion is based on practical considerations rather than the ideological concerns of the cultural turn in Translation Studies, considering that games such as Oblivion have prequels and sequels named after toponyms of the in-game world. The non-translation strategy becomes preferable as the toponyms became game titles which in turn became trademarks (Daggerfall, Morrowind and Skyrim in this particular case) during the course of the Elder Scrolls series (Roh 2011, 87). On average, 68.1\% of 
2018. JIAL: The Journal of Internationalisation and Localisation, 5:1, 101-137.

the respondents of the survey support a foreignising approach when it comes to the translation of names, places and other cultural references.

Table 11 Opinion of the respondents regarding censorship of offensive content in video game localisation

\begin{tabular}{|c|c|c|c|c|c|c|}
\hline & \multicolumn{5}{|c|}{$\begin{array}{l}\text { Q5g-The content deemed offensive should always be } \\
\text { censored during the localisation process of a video } \\
\text { game. }\end{array}$} \\
\hline & & $\begin{array}{c}\text { Fully } \\
\text { agree }\end{array}$ & Agree & Neutral & Disagree & $\begin{array}{c}\text { Fully } \\
\text { disagree }\end{array}$ \\
\hline \multirow[t]{4}{*}{ Nationality } & Canadian & $1.4 \%$ & $3.1 \%$ & $10.3 \%$ & $21.6 \%$ & $63.7 \%$ \\
\hline & French & $1.1 \%$ & $8.1 \%$ & $15.5 \%$ & $22.1 \%$ & $53.1 \%$ \\
\hline & Belgian & $1.9 \%$ & $4.7 \%$ & $12.3 \%$ & $26.4 \%$ & $54.7 \%$ \\
\hline & Swiss & $5.3 \%$ & $3.5 \%$ & $12.3 \%$ & $33.3 \%$ & $45.6 \%$ \\
\hline \multirow[t]{2}{*}{ Global } & Total & $1.9 \%$ & $5.1 \%$ & $12.4 \%$ & $23.2 \%$ & $57.4 \%$ \\
\hline & Mean & $2.4 \%$ & $4.9 \%$ & $12.6 \%$ & $25.9 \%$ & $54.3 \%$ \\
\hline
\end{tabular}

The censorship of offensive content will also be encompassed within the cultural and linguistic movements involved in the localisation of a game title. Culturally offensive elements are identified, sorted and assessed on their potential impact on the target culture (Chandler and Deming 2012, 30). This assumption is based on the idea that religious cultures such as Saudi Arabia or authoritarian regimes like China are intolerant to elements that could 
2018. JIAL: The Journal of Internationalisation and Localisation, 5:1, 101-137.

potentially challenge the dominant ideology. Table 11 displays the opinion of the participants on the statement of Q5g regarding whether or not the culturally offensive content should be censored during localisation. As expected from Q5f and the participant's opinion on the translation of cultural content, the results show that the respondents of all locales are almost unanimous in their refusal of censorship of any form in video games. Although, an analysis of the ideological factors underlying the stance of French-speaking gamers against censorship could provide some insights, the results should also be analysed under the light of the domestication versus foreignisation debate where users will be seeking an experience that is as close to the original as possible because censorship is perceived as watering down the experience. 
Table 12 Opinion of the respondents regarding the general quality of

\section{French video game localisation}

\begin{tabular}{|c|c|c|c|c|c|c|}
\hline & \multicolumn{5}{|c|}{$\begin{array}{l}\text { Q5h-The overall quality of the French adaptation of video } \\
\text { games is generally satisfying. }\end{array}$} \\
\hline & & $\begin{array}{l}\text { Fully } \\
\text { agree }\end{array}$ & Agree & Neutral & Disagree & $\begin{array}{c}\text { Fully } \\
\text { disagree }\end{array}$ \\
\hline \multirow[t]{4}{*}{ Nationality } & Canadian & $2.7 \%$ & $28.4 \%$ & $28.4 \%$ & $31.2 \%$ & $9.2 \%$ \\
\hline & French & $3.7 \%$ & $32.8 \%$ & $32.1 \%$ & $28.0 \%$ & $3.3 \%$ \\
\hline & Belgian & $4.7 \%$ & $44.3 \%$ & $29.2 \%$ & $16.0 \%$ & $5.7 \%$ \\
\hline & Swiss & $5.3 \%$ & $47.4 \%$ & $28.1 \%$ & $17.5 \%$ & $1.8 \%$ \\
\hline \multirow[t]{2}{*}{ Global } & Total & $3.8 \%$ & $33.4 \%$ & $30.3 \%$ & $26.3 \%$ & $6.2 \%$ \\
\hline & Mean & $4.1 \%$ & $38.2 \%$ & $29.5 \%$ & $23.2 \%$ & $5 \%$ \\
\hline
\end{tabular}

Table 12 displays the results of Q5h regarding the perception of the general quality of the French localisation of video games. An opinion on the quality of a given translation should be treated as a subjective matter and considering that the notion of equivalence in translation as a qualitative judgement is an, although necessary, illusionary paradigm (Pym, 2010: 167), there is little insight to be gained in the analysis of this kind of judgement alone. For video games, the quality of a localisation has probably less impact on sales considering that many consumers preorder copies of video games based on what they already know of the product through media, franchises or the reputation of the publisher (Gagnon 2013, 68). 


\section{Discussion}

The working hypothesis of this research was that the linguistic preferences of French video game players from multilingual locales such as Belgium, Canada, and Switzerland are different from those of Frenchspeaking gamers originating from a monolingual country such as France. By gathering clues of preference for non-translation and foreignising translation strategies amongst gamers from French multilingual locales and opposing them to results from French gamers of monolingual locales, the intended objective was to help define localisation strategies that would better suit the needs of the end user and highlight trends to shape successful localisation strategies for other French-speaking locales.

Reflecting on the results of sections 3 to 5, the hypothesis has proven to be only partially correct. In fact, the proposition mainly holds true to describe Francophone gamers from Canada while a higher percentage of the participating French-speaking gamers from Belgium and Switzerland consume foreign language products mainly through French translation, at a proportion that is even higher than the respondents from France. One of the main factors which explain the inclination for French translation amongst the 
European participants from Belgium and Switzerland is the lower level of confidence in English proficiency found in these populations as opposed to the global average.

For the Canadian participants, one of the main underlying reasons for a marked preference for video games in English can be simply explained by the predominance of this language in the North-American context. Canada being officially a bilingual English-and-French-speaking country, the average level of self-assessed English proficiency of Canadians was higher than the rest of the sample which favourably impacted their attitude towards English original products. To express their dissatisfaction, some Canadian participants, although they were Francophones, went as far as to willingly undermine French translation and adaptations of MIES in the questionnaire. Question $4 \mathrm{~b}$ and $4 \mathrm{c}$ have shown the participants from Canada would also choose the French version if a game was developed in French and, more importantly in regard to the hypothesis, would prefer to play a game in a language that befits the context in which the game's narrative takes place. The results echo the findings of Geurts (2014) regarding the Dutch's preference for original content due to a dissatisfaction of localised content and Fernández Costales' research highlighting the preference for English source video game content due to higher level of English proficiency (2016).

Even if the primary hypothesis has been proven partially true and confirmed that some native speakers of French from multilingual locales 
would rather play MIES in English, the goal of this study was not to provide data regarding the success or failure of video game localisation in the Frenchspeaking markets of the Northern hemisphere. This research is focussed on defining what the audience of video games consider as potential best practices; 'the reception of AV output is not only about cultural assumptions, allusions or proper names_-but also about expectations' (Gambier 2003,186). The fact that amongst the studied population there is a difference in the levels of self-assessed English proficiency is a mark of variation within language groups, although it should be stressed that language proficiency alone is not the sole criterion that will define the linguistic preferences of a given player. Studies have shown that some players experience games in languages they cannot understand just for their own entertainment while barely learning the language of the game they play (Smith 2014).

The inclination towards subtitles of the surveyed population does not signify the 'death of dubbing' considering that a significant proportion of the participants still relies on dubbing, even more so when the product is in a language other than English. This is, of course, related to the notion that reading subtitles requires more effort on the audience's part as 'the greater the viewers' processing effort, the lower the relevance of the translation' (Gambier 2003, 185). Although a majority of participants preferred subtitles over dubbing, some still stated that games such as Borderlands 2, Dawn of 
War, and Portal 2 received a high-quality treatment during localisation as they enjoyed the dubbed versions.

Even if most MIES customisable settings offer some degree of linguistic personalisation, they seldom fail at offering a localisation experience as customisable as other elements of the user interface. For example, the language of the audio assets should be independent of the language chosen for the subtitles, allowing the player to participate in a personalised immersive cultural and linguistic experience unlike any others. Such is the case with some products like the Wolfenstein: The New Order or the Metro series but it does not apply to all localisations. Another option is that games that deal with multinational topics, like Medieval Total War II series, could provide "immersive" linguistic settings by allowing the user to choose the option of native languages audio for all the cultures represented in the games with inter-lingual subtitles instead of the culturally insensitive approach of using different stereotypical accents in English to convey linguistic groups. The most recent iterations of the Civilisation series offered such level of immersion as other world leaders controlled by the artificial intelligence would address the player in their respective native languages. The idea of giving MIES users the possibility of enjoying an immersive linguistic experience should be one of the concerns of the video game industry, not only because it should be part of best practices in translation but also because it is what a majority of gamers want, based on the results of this study. 


\section{Conclusion}

Throughout this study, the notion that the receptor of the translation should be the main focus for localised products has been stressed to highlight the fluid preferences of the user base when it comes to linguistic content. Through the exploration of the data, this study has shown that the Francophone gaming community studied is akin to what Media Studies researchers have labelled as "fandom": a highly critical and mobilised consumer base whose impact on the entertainment industry should be factored in the production of content. While the first hypothesis has been proven to be partially true, the results of this foray into the reception of localised video games are a clear expression of the difference in the range of attitudes amongst French-speaking gamers, even within the same locale. Where linguistic community are usually considered as monolithic cultural constructs when it comes to localised products, the validation of the secondary hypothesis has shown that there are more factors that shape the attitudes of a community towards a given cultural production than the use of a common language within set geographical borders. This variety in preferences is an expression of the contemporary attitude of global audiences towards entertainment where freedom of choice 
in content, medium (Lieberman and Esgate 2014, 277) and the way the product is consumed interlingually is of utmost importance to the public.

The study has also shown that the Francophone gaming community is inclined towards particular translation strategies as a clear majority of the participants agreed to favour subtitling over dubbing, foreignisation over domestication strategies in translation, and they almost unanimously disagree with the concept of censorship. These findings are similar to the conclusions drawn by Geurts (2015) and Fernández Costales (2016) and are not only related to a dismissive attitude towards translated material, they also express a desire for the audience to experience the original narrative. Such a strong preference is also a mirror of the cultural production in the Western world, where a syncretic cosmopolitan American culture is responsible for most of our semiosphere (Camboni et al. 2011) but it is also an echo of a particularity of video gaming as a universe. In the constantly connected gaming multiverse, gaming fandoms turn into quantum nations: 'spontaneous associations of individuals that supersede geopolitical borders and space time' (Bernal-Merino 2016a, 203). The cultural syncretism of video games transcends individuals and communities and is also now part of the fabric of the product itself as 'game creation is now unmoored from national borders and cultures, and has become its own sphere of influence, defining its own technoregion' (Consalvo 2006, 133). 


\subsection{Recommendations}

Based on the data collected in this study and previous literature on preferable best practices in video game localisation (Ellefsen 2015; Roh 2011), the results gathered in this research can be used to submit recommendations to the industry.

1. Engage: The community is more than willing to collaborate in the elaboration of best practices for successful video game localisation. The volume of answers to the survey of the present research is a clear indicator of the community's desire to provide feedback. Moreover, adding to the cooperative nature of the community, the fact that some early-access development models have become very successful and lucrative endeavours (Green 2016) is a testimony to the potential of a strong link between developers and players in the creation of successful games. To improve the quality of localised video games, publishers should implement means of communicating with the community, following processes not unlike UCT to create an ongoing feedback loop and continuously enhance the quality of their products.

2. Standardise: While television and film industries have struggled in the past to adopt standards regarding subtitles, there are now clearer guidelines as to what the best practices in subtitling are (Katamitroglou 1998). Yet, the video game industry still lags behind and the subtitles offered in 
2018. JIAL: The Journal of Internationalisation and Localisation, 5:1, 101-137.

games are generally disappointing being too long for the reader to capture entirely (Bernal-Merino 2015, 133) or not displaying any sort of conventions whatsoever, negatively impacting the game experience (Mangiron 2013, 52). Norms of standardisation should also be applied to subtitling and any linguistic element such as in-text game and user interface, voice overs and dubbing.

3. Personalise: Give more choice to the players as to how they want to experience the narrative through dubbing, subtitling, partial translation or non-translation. Considering that some games offer a customisable setting regarding the display of violent acts or sexual content (Dragon Age: Origins) or allow the user to reorganise the user interface (World of Warcraft), language customisation seems like a logical requirement.

\subsection{Limitations and Suggestion for Future Research}

This study should not be regarded as a completely accurate representation of the Francophone gaming community. Even if the research has the biggest sample collected so far on the topic, there are some issues of underrepresentativeness notably amongst the Belgian and Swiss French-speaking population and over-representativeness of French-Canadians which should be addressed to provide more accurate results. A bigger sample would normalise 
the results and provide more insights into what the wider French-speaking gaming community expects of video games.

One of the biggest gaps in the research is that it focusses mainly on games developed in English and leaves Japanese productions aside. Considering that companies such as Nintendo and Sony are major stakeholders in the industry, many games are developed in Japanese and the English localisation is used as a pivot for all the other languages. One of the reasons to avoid involving further the Japanese game market in the research was to narrow down the content to Western production and work through the English-to-French lens. Although, in light of the results of Q4c, there is a possibility that French gamers would play Japanese games with the original audio and interlingual subtitles the same way they do with Western "foreign" content.

As stated earlier, because the study is limited to mainly English and French language products and surveys French-speaking natives, the scope of the research remains narrow, especially within modern multicultural states. The opinion of migrants on language preferences should be investigated as it could provide information on national language adoption by newcomers and cultural minorities. Moreover, another possible expansion of the research would be to survey other languages to see if there is a difference in the attitudes and preferences in language settings for other locales. While the FIGS language context could be more or less the same as the results for French locales, the situation might be totally different for locales situated in 
Scandinavia or in the Middle East as those regions have different levels of English proficiency or varied tolerance to material that is culturally foreign or potentially offensive.

While this study is mainly a quantitative exploration, further analysis should be conducted to explain the underlying causes behind the results obtained. Qualitative data should be useful in complementing the collected data to provide adequate explanations to justify the choices, which was one of the main critics addressed by the participants. Interviews and more openended questions could provide insights as to what really motivates the choices of the respondents.

Finally, the type of game played should be relevant for a proper analysis of linguistic preferences of players. While the jury is still out on a proper taxonomy of gaming genres, based on gameplay and the game's setting, the possibility of evaluating the approach for localisation based on a classification of video games with regards to the content to be localised could be investigated. For example, dialogue and mechanics-heavy games like Role-playing games or strategy games would necessarily require different approaches to translation than cinema-like story driven adventure games.

7.3 Final Thoughts 
Even if the user has been central in this analysis, the implications of this exploration should not be regarded as crowning players as all-powerful and dismissing the opinions of academics and professionals in a debate between descriptive and prescriptive conceptions of translation. The emphasis should be on the idea that language professionals should be made aware of the opinion voiced by consumers in an iterative fashion. Language preference data should be analysed the same way customer service is considered, to constantly improve the quality of the linguistic transfer. This information would help language professionals in their practice and connect content producers, translators and their audiences.

In this regard, the present study can be used to support improvements in the translation and localisation industry across all mediums and locales. It is through the analysis of data that future best practices and standards will be defined. For the video game industry, the research also stresses the significance of video games as cultural artefacts through their importance for the consumers. Hopefully, further research on the reception of MIES can influence the legislative bodies and the industry to eventually transform the localisation process into a cultural-preservation-endeavour which would empower developers, translators and consumers alike. 
2018. JIAL: The Journal of Internationalisation and Localisation, 5:1, 101-137.

\section{Bibliography}

Bartelt-Krantz, Michaela. 2011. “Game Localization Management:

Balancing linguistic quality and financial efficiency." Trans, (15):

83-88.

Bernal-Merino, Miguel Ángel. 2015. Translation and Localisation in Video

Games: Making Entertainment Software Global. New York:

Routledge, Taylor \& Francis Group.

Bernal-Merino, Miguel Ángel. 2016a. “Glocalization and Co-Creation.

Trends in International Game production" in Smith, I.R., Bernal-

Merino, M. Á. \& Esser, A. eds. Media Across Borders: Localizing

TV, Film, and Video Games. New York: Routledge, Taylor \&

Francis Group: 202-220.

Bernal-Merino, Miguel Ángel. 2016b. "Using semiotics and Pragmatics to

Explain the Complexity of Video Game Localisation.” Signata,

Annales des Sémiotiques $=$ Annals of semiotics $:$ 232-253.

Beuré, Fanny, et al. 2014. Les Pratiques De Consommation De Jeux Vidéo

Des Français. Paris : Centre national du cinéma et de l'image animée. 
2018. JIAL: The Journal of Internationalisation and Localisation, 5:1, 101-137.

Bug Tracker. 2017. Bug Tracker Loc \& QA. http://bug-tracker.com/ Accessed 09/20/2017, http://bug-tracker.com/.

Bushouse, Elizabeth. 2015. The Practice and Evolution of Video Game Translation: Expanding the Definition of Translation. University of Massachusetts. Accessed 15/07/2016, http://scholarworks.umass.edu/cgi/viewcontent.cgi?article=1218\&co $\underline{\text { ntext }=\text { masters } \_ \text {theses } 2}$

Caimi, Annamaria. 2006. "Audiovisual translation and language learning: The promotion of intralingual subtitles." In The Journal of Specialised Translation. (6):85-98.

Camboni, Marina, et al., eds. 2011. "Translating America: The Circulation of Narratives, Commodities, and Ideas between Italy, Europe, and the United States." Transatlantic Aesthetics and Culture, 5, Peter Lang: Bern.

Chandler, Heather Maxwell, and Stephanie O’Malley Deming. 2012. The Game Localization Handbook. Hingham, Mass: Charles River Media.

Chatfield, Tom. 2009. "Videogames now outperform Hollywood movies". The Guardian, $27^{\text {th }}$ September 2009. Accessed 12/06/2016. https://www.theguardian.com/technology/gamesblog/2009/sep/27/vi deogames-hollywood. 
2018. JIAL: The Journal of Internationalisation and Localisation, 5:1, 101-137.

Consalvo, Mia. 2006. "Console video games and global corporations creating a hybrid culture." New Media \& Society. 8 (1):117-137.

Damasco, Flavio. 2014. Casual Gamers Vs Hardcore Gamers. Accessed $13 / 06 / 2016$

http://www.gamasutra.com/blogs/FlavioDamasco/20140224/211502/ $\underline{\text { Casual_gamers_vs_hardcore_gamers.php. }}$

Danaan, Martine. 2004. "Captioning and subtitling: Undervalued language learning strategies." Meta: Journal Des traducteurs/Meta :Translators' Journal. 49 (1): 67-77.

Dietz, Frank. 2007. "How Difficult Can That Be? The Work of Computer and Video Game Localization”. Revista Tradumàtica 5: “Localització de videojocs”. Accessed: 08/08/2016 https://ddd.uab.cat/pub/tradumatica/15787559n5/15787559n5a4.pdf

Education First. 2015. English Proficiency Index. Education first. Accessed: 21/07/2016. http://www.ef.co.uk/epi/.

Edwards, Kate. 2011. "Culturalization: The geopolitical and cultural dimension of game content.” Trans. (15):19-28.

Ellefsen, Ugo. 2015. Between Reality and (Science) Fiction: French Localisation of the Post-Apocalyptic American dream. Unpublished Essay, London. 
2018. JIAL: The Journal of Internationalisation and Localisation, 5:1, 101-137.

Entertainment Software Association. 2017. Essential Facts about the computer and video game industry. Accessed 20/09/2017 http://www.theesa.com/wpcontent/uploads/2017/09/EF2017_Design_FinalDigital.pdf.

Fernández Costales, Alberto. 2016. “Analyzing Player’s Perception on the Translation of Video Games.” in Andrea Esser, Miguel Ángel Bernal-Merino, and Iain R. Smith. eds. Media Across Borders: Localizing TV, Film, and Video Games. New York: Routledge, Taylor \& Francis Group: 183-201.

Gagnon, Claudia. 2013. Le Jeu Vidéo Comme Modèle De Légitimation De La Localisation. Concordia University. Accessed: 15/06/2016 http://spectrum.library.concordia.ca/977481/1/Gagnon_MA_F2013.p df.

Gambier, Yves. 2003. "Introduction: Screen transadaptation: Perception and reception." The Translator. 9 (2):171-189.

Geurts, Francine. 2015. What do You Want to Play? The Desirability of Video Game Translations from English into Dutch According to Dutch Gamers and Non-Gamers. Leiden University. Accessed $15 / 06 / 2016$ https://openaccess.leidenuniv.nl/bitstream/handle/1887/34704/Comp lete\%20thesis $\% 202015-07-20 \% 20$ final.pdf?sequence $=1$ 
2018. JIAL: The Journal of Internationalisation and Localisation, 5:1, 101-137.

Green, Holly. 2016. 7 Successful Early Access Games that all Developers should Study. Accessed 14/07/2016.

http://www.gamasutra.com/view/news/275719/7_successful_Early_ Access_games_that_all_developers_should_study.php.

Game Developers Conference. 2017. Localization Summit. Accessed: 20/09/2017) http://www.gdconf.com/conference/gls.html.

IGDA Game Localization SIG. 2017. Best practices for Game Localization. Accessed 20/09/2017. http://www.igda.org/members/group_content_view.asp?group=1210 $\underline{45 \& \mathrm{id}=526230 .}$.

Jayanth, Meg. 2014. " $52 \%$ of gamers are women—-but the industry doesn't know it.” The Guardian, September 2014. Accessed 20/06/2016 https://www.theguardian.com/commentisfree/2014/sep/18/52percent-people-playing-games-women-industry-doesnt-know.

Jenkins, Henry. 2013. Textual Poachers: Television Fans and Participatory Culture. New York, London: Routledge.

Karamitroglou, Fotios. 1998. “A proposed set of subtitling standards in Europe.” Translation journal, 2 (2): 1-15.

Keywords Studios. 2017. Keywords Studios. Accessed 20/09/2017. http://www.keywordsstudios.com/en. 
2018. JIAL: The Journal of Internationalisation and Localisation, 5:1, 101-137.

Laurent, Flavie. 2015. "Les plus mauvaises localisations de jeux vidéo. Veille CFTTR Traduction, Rédaction, Localisation.” March. Accessed: 16/08/2016. http://www.sites.univrennes $2 . \mathrm{fr} / \mathrm{lea} / \mathrm{cfttr} / \mathrm{veille} / \mathrm{p}=1674$

Lieberman, Al, and Patricia Esgate. 2014. The definitive guide to Entertainment Marketing, Upper Saddle River, New Jersey: FT Press.

Loc World. 2017. Game Localization Roundtable, Accessed, 20/09/2017, http://locworld.com/sessions/game-localization-round-table/.

Mandiberg, Stephen. 2012 "Translation and/as Interface.” Loading... The Journal of the Canadian Game Studies Association. 6 (10): 53-70

Mangiron, Carmen. 2013. "Subtitling in game localisation: A descriptive study." Perspectives. 21 (1): 42-56.

Mangiron, Carmen. 2007. "Video games localisation: Posing new challenges to the translator." Perspectives. 14 (4): 306-323.

Media Across Borders. 2017. Media Across Borders. Accessed: 20/09/2017. http://mediaacrossborders.com/.

Newzoo. 2017. The Global Games Market Will Reach \$108.9 Billion in 2017 With Mobile Taking 42\%. Accessed 18/09/2017 
2018. JIAL: The Journal of Internationalisation and Localisation, 5:1, 101-137.

https://newzoo.com/insights/articles/the-global-games-market-willreach-108-9-billion-in-2017-with-mobile-taking-42/

Newzoo. 2017. Top 100 Countries by Game Revenues. Accessed: 20/09/2017. https://newzoo.com/insights/rankings/top-100-countriesby-game-revenues/.

O’Hagan, Minako. 2007. "Video games as a new domain for translation research: From translating text to translating experience." Tradumàtica: Traducció i Tecnologies De La Informació i La Comunicació. (5).

O’Hagan, Minako, and Carmen Mangiron. 2006. "Game localisation: Unleashing imagination with 'restricted' translation.” The Journal of Specialised Translation. 6:10-21.

O’Hagan, Minako. 2009. “Towards a cross-cultural game design: An explorative study in understanding the player experience of a localised Japanese video game.” The Journal of Specialised Translation. 11: 211-233.

O'Hagan, Minako, and Carmen Mangiron. 2013. Game Localization: Translating for the Global Digital Entertainment Industry. John Benjamins Publishing. 
2018. JIAL: The Journal of Internationalisation and Localisation, 5:1, 101-137.

Pole to Win. 2016. Pole to Win. Accessed: 08/08/2016. https://www.ptwi.com/.

Pym, Anthony. 2010. Exploring Translation Theories. London : Routledge.

Roh, Florence. 2011. Les Effets Des Erreurs De Traduction Dans La

Localisation Des Jeux Vidéo (L'Exemple de The Elder Scrolls : IV

Oblivion). University of Geneva. Accessed 20/07/2016.

https://archive-ouverte.unige.ch/unige:17295/ATTACHMENT01.

Rose, John. 2008. Fewer Mechanics, Better Game. Gamasutra. Accessed $13 / 07 / 2016$

http://www.gamasutra.com/view/feature/132022/fewer_mechanics_b etter_game.php.

Smith, Gabriel Edward. 2014. Playing Video Games in Japanese:

Motivation, Language Learning, and Navigation. Concordia

University. Accessed: 25/06/2016.

http://spectrum.library.concordia.ca/978419/1/Smith_MA_S2014.pd

$\underline{\mathrm{f}}$

Suojanen, Tiina, Kaisa Koskinen and Tytti Tuominen. 2014. User-Centered Translation. Routledge.

Testronics. 2016. Testronics - Quality Assurance, Localization Services and Certification. Accessed: 08/08/2016. http://www.testroniclabs.com/ 
2018. JIAL: The Journal of Internationalisation and Localisation, 5:1, 101-137.

Valve Corporation. 2017 Steam Hardware \& Software Survey: August 2017. Accessed: 09/20/2017. http://store.steampowered.com/hwsurvey.

\section{Ludography}

4A Games. 2013. Metro 2033, THQ and Deep Silver.

4A Games. 2013. Metro: Last Light, Deep Silver.

Bethesda Softworks. 1996. The Elder Scrolls Chapter II: Daggerfall, Bethesda Softworks and Ubisoft.

Bethesda Game Studios. 2002. The Elder Scrolls III: Morrowind, Bethesda Softworks and Ubisoft.

Bethesda Game Studios. 2006. The Elder Scrolls IV: Oblivion, Bethesda Softworks.

Bethesda Game Studios. 2011. The Elder Scrolls V: Skyrim, Bethesda Softworks.

Bit Managers. 1993. Astérix, Infogrames.

BioWare. 2009. Dragon Age: Origins, Electronic Arts.

Blizzard Entertainment. 2004. World of Warcraft, Blizzard Entertainment.

The Creative Assembly. 2006. Medieval II: Total War, Sega.

Firaxis Games. 2010. Civilisation V, 2K Games. 
2018. JIAL: The Journal of Internationalisation and Localisation, 5:1, 101-137.

Gearbox Software. 2015. Borderlands 2, 2K Games.

MachineGames. 2014. Wolfenstein: The New Order, Bethesda Softworks.

Relic Entertainnment. 2004. Dawn of War, THQ.

Square.1997. Final Fantasy VII, Square, Sony Computer Entertainment and Eidos.

Ubisoft Montréal. 2009. Assassin's creed II, Ubisoft.

Ubisoft Montpellier. 1995. Rayman, Ubisoft.

Valve Corporation. 2012. Counter Strike: Global Offensive, Valve Corporation.

Valve Corporation. 2013. Dota 2, Valve Corporation.

Valve Corporation. 2011. Portal 2, Valve Corporation and Electronic Arts. 